\title{
Dysphagia caused by migrated mesh after paraesophageal hernia repair
}

The placement of expanded polytetrafluoroethylene (ePTFE) mesh to reinforce the crural hiatal closure in laparoscopic antireflux surgery, has proved to be useful in preventing hiatal hernia recurrence and reducing the risk of postoperative migration of the wrap into the chest [1].

We report the case of a 71-year-old woman who was referred for progressive dysphagia and weight loss 2 years after undergoing Nissen fundoplication with the placement of a ePTFE mesh for a large paraesophageal hernia. An esophagogram ( $\bullet$ Fig. 1) revealed multiple air bubbles in the upper esophagus, with passage of contrast into the bronchial tree. The radiological contrast flowed into the stomach thorough a stenosis of about $1 \mathrm{~cm}$ in diameter. Endoscopy revealed a mesh located at $22 \mathrm{~cm}$ from the dental arch in the esophageal lumen, like a prosthesis that had rotated on its axis ( Fig. 2). The mesh was firmly fixed and impossible to move, preventing the progression of the endoscope. Because of the patient's age, associated comorbidity, the impossibility of endoscopic treatment, and the complexity of possible surgery, a decision was made to commence palliative treatment and a gastrostomy was created without any other complications.

Although the use of ePTFE mesh in the laparoscopic surgical repair of hiatal hernia has proved to be safe, migration into the chest cavity is a rare complication, comprising approximately $0.5 \%$ of complications in large series [2]. In exceptional cases, transmural migration into the gastrointestinal tract has been observed [3-5]. Dysphagia in the immediate postoperative period is common in these patients and should disappear in the short term; however, if dysphagia occurs later, as in our patient, migration of the prosthesis into the thoracic cavity or transmural dislodgment towards the lumen of the upper gastrointestinal tract should be ruled out.

Endoscopy_UCTN_Code_CCL_1AB_2AC_3AH

Competing interests: None

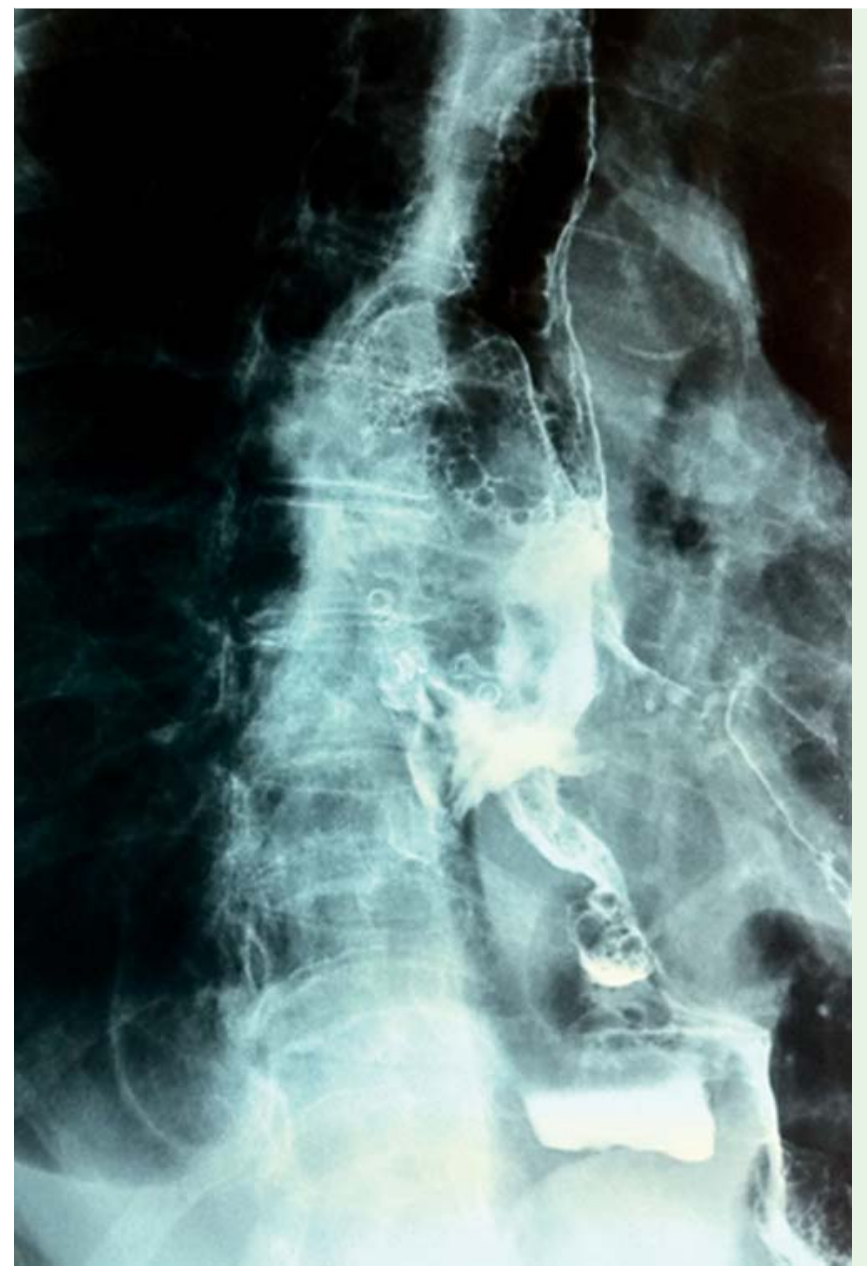

Fig. 1 Esophagogram showing multiple air bubbles in the upper esophagus with passage of contrast into the bronchial tree, and distal stenosis with a sliding hiatal hernia.

Q. Arroyo ${ }^{1}$, F. Argüelles-Arias ${ }^{1}$, M. Jimenez-Saenz ${ }^{2}$, J. M. HerreriasGutierrez $^{2}$, F. Pellicer Bautista ${ }^{3}$

1 Division of Digestive Diseases, Virgen Macarena University Hospital, Seville, Spain

2 Division of Gastroenterology, Virgen Macarena University Hospital, Seville, Spain

3 Endoscopy Unit, Virgen Macarena's Hospital, Seville, Spain

\section{References}

1 Zilberstein B, Eshkenazy R, Pajecki D et al. Laparoscopic mesh repair antireflux surgery for treatment of large hiatal hernia. Dis Esophagus 2005; 18: 166-169

2 Soricelli E, Basso N, Genco A et al. Long-term results of hiatal hernia mesh repair and antireflux laparoscopic surgery. Surg Endosc 2009; 23: 2499-2504

3 Coluccio G, Ponzio S, Ambu V et al. Dislocation into the cardial lumen of a PTFE prosthesis used in the treatment of voluminous hiatal sliding hernia. A case report. Minerva Chir 2000; 55: 341 - 345

4 Hergueta-Delgado P, Marin-Moreno M, Morales-Conde $S$ et al. Transmural migration of a prosthetic mesh after surgery of a paraesophageal hiatal hernia. Gastrointest Endosc 2006; 64: 120-121

5 Carpelan-Holmström M, Kruuna O, Salo J et al. Late mesh migration through the stomach wall after laparoscopic refundoplication using a dual-sided PTFE/ePTFE mesh. Hernia 2011; 15: $217-220$ 

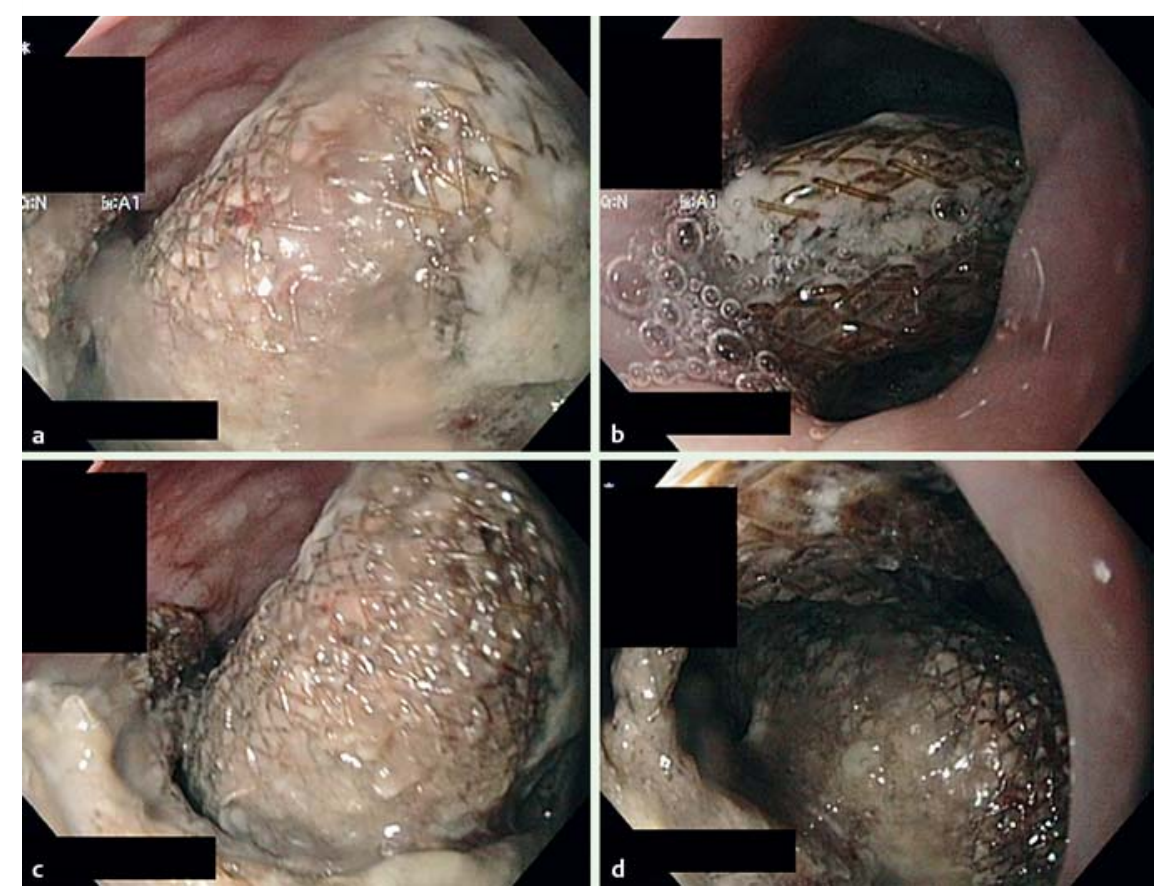

Bibliography

DOI $10.1055 / \mathrm{s}-0030-1256520$

Endoscopy 2011; 43: E257-E258

(c) Georg Thieme Verlag KG Stuttgart · New York .

ISSN 0013-726X

\section{Corresponding author \\ Q. Arroyo}

Division of Digestive Diseases

Virgen Macarena University Hospital

Seville

Spain

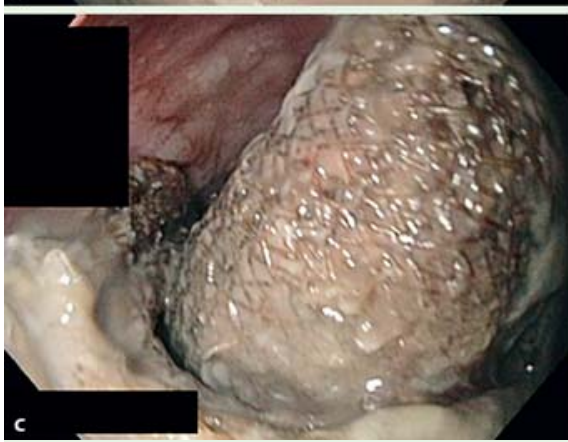

quetzalihuit|@hotmail.com

Fig. 2 A migrated mesh is seen in the esophagus, occupying the lumen as a 'prosthesis' that had rotated on its axis. 